[Agr. Biol. Chem., Vol. 35, No. 3, p. 444, 1971]

\title{
6,8-O-Dimethylversicolorin A, a New Metabolite from Aspergillus versicolor
}

Sir:

We have reported the isolation and structures of five anthraquinoid pigments, versicolorin $\mathrm{A}, \mathrm{B}, \mathrm{C}$, versiconol, and norsolorinic acid, from the mycelium of Aspergillus versicolor (Vuillemin) Tiraboschi. ${ }^{11}$ Further investigation of this mold has resulted in the isolation of a new metabolite, 6,8-O-dimethylversicolorin A (I) the structure of which was established by chemical and spectrometric methods.

The new metabolite forms yellow needles when recrystallized from acetone, $m p 285^{\circ} \mathrm{C}$ (decomp.), $[\alpha]_{\mathrm{D}}^{25}-320^{\circ}$ ( $c=0.12$, dioxane). Anal. Found: $\mathrm{C}, 65.77 ; \mathrm{H}, 3.86$; MS m/e: $366\left(\mathrm{M}^{+}\right)$. Calcd. for $\mathrm{C}_{20} \mathrm{H}_{14} \mathrm{O}_{7}: \mathrm{C}, 65.57 ; \mathrm{H}, 3.85,6 ;$ M.W. 366. UV $i_{\mathrm{max}}^{\mathrm{EtoH}} \mathrm{m} \mu(\varepsilon): 223(47,900), 250(18,200)$, $282(46,800), 312(10,700), 435$ (11,200). IR ${ }_{\max }^{\mathrm{KBr}} \mathrm{cm}^{-1}: 1665,1640,1615,1600$. The infrared spectrum of I showed bands at 1665 and $1640 \mathrm{~cm}^{-1}$ indicating the presence of nonchelated and chelated anthraquinone carbonyl groups. Acetylation of I gave a monoacetate (II), mp $228^{\circ} \mathrm{C}$. Anal. Found: C, 64.71; H, 3.93. Calcd. for $\mathrm{C}_{22} \mathrm{H}_{16} \mathrm{O}_{8}: \mathrm{C}, 64.70 ; \mathrm{H}, 3.95 \%$. The NMR spectrum of II shows singlet resonances at $7.48,6.05$ and $6.04 \tau$ due to the methyl protons of acetyl and two methoxyl groups, respectively. The spectrum of II shows signals at $5.38=(1 \mathrm{H}$, triplet of doublets, $J=2.5$ and $7 \mathrm{cps}), 4.78 \tau$ ( $1 \mathrm{H}$, triplet, $J=2.5 \mathrm{cps}), 3.52 \tau$ ( $1 \mathrm{H}$, triplet, $J=2.5 \mathrm{cps})$ and $3.22 \tau(1 \mathrm{H}$, doublet,

1) T. Hamasaki, Y. Hatsuda, N. Terashima and M. Renbutsu, Agr. Biol. Chem., 31, 11 (1967); T. Hamasaki, M. Renbutsu and Y. Hatsuda, ibid., 31, 1513 (1967); Y. Hatsuda, T. Hamasaki, M. Ishida and S. Yoshikawa, ibid., 33, 131 (1969).
$J=7 \mathrm{cps}$ ). These signals were assigned to the four protons of the dihydrodifurano ring system, and signals at $3.26 \tau(1 \mathrm{H}$, doublet, $J=$ $2.5 \mathrm{cps}), 2.65 \tau(1 \mathrm{H}$, doublet, $I=2.5 \mathrm{cps})$ and $2.40 \tau(1 \mathrm{H}$, singlet) were assigned to aromatic ring system.

Methylation of I gave a methylether, $\mathrm{mp}$ $246^{\circ} \mathrm{C}$ (III). Anal. Found: C, 65.88; H, 4.19. Calcd. for $\mathrm{C}_{21} \mathrm{H}_{16} \mathrm{O}_{7}: \mathrm{C}, 66.31 ; \mathrm{H}, 4.24 \%$. Compound III was established to be O-trimethylversicolorin A by comparison with an authentic sample derived from the methylation of versicolorin A. ${ }^{11}$

Oxidation of $\mathrm{I}$ with $\mathrm{CrO}_{3}$ gave crystalline solid, $\mathrm{mp} 157^{\circ} \mathrm{C}$, which was identical with synthetic 3,5-dimethoxyphthalic acid.

Thus, the structure of $\mathrm{I}$ is 6,8-O-dimethylversicolorin $\mathrm{A}$.

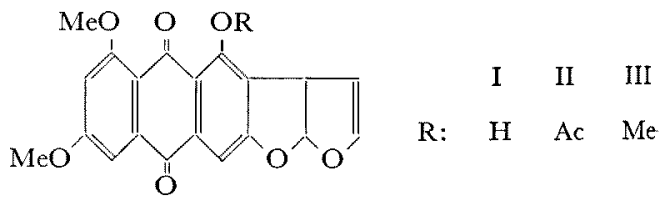

We wish to thank Dr. G. Sunagawa, Central Research Laboratory Sankyo Co., Ltd., for the elemental analysis and measurement of NMR spectra.

Yuichi HATSUDA

Takashi HamasakI Masayoshi ISHIDA Yukiho KIYAMA

Faculty of Agriculture, Tottori University,

Tottori, Japan

Received December 14, 1970 